\title{
LA LIBERTAD SINDICAL DE JUECES, MAGISTRADOS Y
} FISCALES

\author{
FERNANDO J. SANZ LLORENTE \\ Profesor de Derecho Sindical \\ Escuela Universitaria de Estudios Sociales \\ VIGO
}


SUMARIO

Introduccion. - I. Planteamiento Constitucional: el debate parlamentaRio del articulo 127 de la Constitución.- 1. La Minoría Catalana. 2. El Grupo Comunista. 3. El Grupo Socialista. 4. EI Grupo Popular. 5. El Grupo Centrista. II. DeSARRollo LegisLaTIVo.- 1. La Ley Orgánica de Libertad Sindical. 2. La Ley de derechos sindicales de los funcionarios públicos. 3. La Ley Orgánica del Poder Judicial. 4. El Estatuto Orgánico del Ministerio Fiscal. III. DISCREPANCIAS DOCTRINALES. - IV. LAS ASOCIACIONES PROFESIONALES. - 1. Antecedentes históricos. 2. Naturaleza jurídica: ¿verdaderos sindicatos? 3. El régimen jurídico. a) Asociaciones de jueces y magistrados. b) Asociaciones de fiscales. V. ConClusiones. - Bibliografia. 


\title{
4. LA LIBERTAD SINDICAL DE JUECES, MAGISTRADOS Y FISCALES
}

\author{
POR \\ FERNANDO J. SANZ LLORENTE \\ Profesor de Derecho Sindical \\ Escuela Universitaria de Estudios Sociales de Vigo
}

\section{INTRODUCCIÓN}

Desde que la Constitución Española de 1978 entró en vigor, la cuestión de la libertad sindical de los jueces, magistrados y fiscales ha suscitado poco interés doctrinal, tal vez debido al elevado grado de conformidad observado por los colectivos afectados, que han aceptado, con una extraña complacencia, la situación teóricamente limitativa que consagró en su texto definitivo la Carta Magna. No parece muy lógico que la negación de un derecho, reconocido sin apenas limitaciones a otros ciudadanos, produzca en. los "agraviados" tal sensación de sumisión, salvo que esta actitud esté motivada por alguna de estas causas: por una parte, el autoconvencimiento de que la alternativa opuesta es imposible, por entenderse que la situación limitativa o restrictiva del derecho es la más lógica, teniendo en cuenta que se desempeña una función profesional cuyo ejercicio libre e independiente pudiera verse empañado en alguna medida por el disfrute del derecho; por otra parte, el inequívoco conocimiento de poder disponer de un derecho análogo al prohibido, cuya titularidad se reconoce sin apenas limitaciones y que, una vez acondicionado y maquillado, producirá en sus titulares idénticos beneficios que el derecho legalmente negado.

Por ello, el título de «libertad sindical» no puede ni debe molestar o sorprender a nadie, pues responde a una mera observación de la realidad. No obstante, pocos se han atrevido a llamarla así y, en general, la doctrina se ha aferrado cómodamente a la denominación legal de "asociacio- 
nismo profesional» para describir este fenómeno. En todo caso, lo que sí puede constatarse actualmente con claridad es que la materia que aquí se analiza dejó de ser un problema (en realidad nunca lo fue), desde el momento en que se reguló constitucionalmente, pasando el legislador a afanarse después en el adecuado desarrollo de las denominadas asociaciones profesionales, una vez que la Constitución habia dejado zanjado el tema con rotundidad en su articulado.

El Derecho Sindical (disciplina jurídica cuya importancia hoy nadie niega dentro del complejo mundo de las relaciones laborales) nos enseña cómo el nacimiento de las primeras leyes sindicales surgió como necesidad contrastada por los Estados de enfrentar y ordenar la realidad cada vez más creciente y extendida del asociacionismo obrero (GARCIA ABELLÁN), hecho que, por otra parte, estimuló la agrupación de los patronos, surgida fundamental y primariamente como instrumento de respuesta a la acción concertada de los trabajadores. De ahí que ambos acontecimientos, contemplados desde la perspectiva del Derecho, dieran lugar a la globalización del fenómeno asociativo, tanto de base profesional (trabajadores) como económica (empresarios), mediante la formulación de un régimen juridico común cuyo denominador, común igualmente, radicaba y radica en concebir la asociación como instrumento de defensa de los respectivos intereses a los que su origen responde.

Es evidente que ni jueces ni fiscales son considerados trabajadores en el ámbito del Derecho del Trabajo, en el sentido de que no se encuentran vinculados a su empresario por un contrato de trabajo. Además, el empresario a quien prestan sus servicios no es otro particular, sino el propio Estado, cuya tendencia ha sido secularmente la de exigir a los empresarios el respeto de los derechos de los trabajadores a su servicio, cuando aquél ha sido por naturaleza reacio a aplicar ese mismo criterio.

Sin embargo, en el ámbito del Derecho Sindical (también denominado Derecho Colectivo del Trabajo y, por tanto, parte integrante del Derecho Laboral), hay una equiparación terminológica entre funcionarios y trabajadores por cuenta ajena en sentido estricto (a los efectos de la Ley Orgánica de Libertad Sindical, «se consideran trabajadores tanto aquellos que sean sujetos de una relación laboral, como aquellos que lo sean de una relación de carácter administrativo o estatutario al servicio de las Administraciones Públicas»; articulo 1.2), después de reconocer el derecho que todos los trabajadores tienen a sindicarse libremente para la promoción y defensa de sus intereses económicos y sociales.

Por todo ello, causa una gran extrañeza esa perfecta sintonía del colectivo judicial afectado con el "empresario" que lo discrimina en el uso y disfrute pacífico de un derecho. ¿O es que realmente no lo discrimina? 


\section{PLANTEAMIENTO CONSTITUCIONAL: EL DEBATE PARLAMENTARIO DEL ARTICULO 127 DE LA CONSTITUCIÓN}

Aunque la tradición nos enseña que, en este punto, habría que abordar, aunque fuera someramente, el aspecto de los precedentes, la realidad no ofrece base para ello pues, como indica SERRANO ALBERCA, las Constituciones españolas no regulaban esta materia; el mismo autor afirma que no es tampoco corriente que el Derecho Constitucional Comparado recoja las prohibiciones impuestas a los jueces. La Constitución italiana, en el artículo 104, se refiere a incompatibilidades de los miembros del Consejo Superior, y la Ley Fundamental de Bonn, en el artículo 94, a incompatibilidades de los jueces.

Sin duda, la mejor manera de comprender hasta qué punto la redacción de cualquier pasaje constitucional es producto del dominio de la mayoría parlamentaria de turno, será analizar con cierto detalle la postura mantenida por los diferentes grupos parlamentarios en el debate del artículo 127 de la Constitución, para comprobar así la relativización de dicho precepto, llegándose a la conclusión de que la teoría política de un partido en concreto impuso, de forma casi dogmática, una particular visión de entender el problema, mientras que no resultará difícil deducir, a la vista de lo que después se dirá, cómo otra teoría política (más bien un partido con siglas distintas, pues las diferencias entre UCD y PSOE no han sido tan grandes en la práctica) hubiera impuesto otro criterio distinto en la redacción del controvertido artículo 127 que estamos analizando.

La redacción del artículo 127.1 de la Constitución fue objeto de sucesivas modificaciones en las Cortes, hasta alcanzar su actual configuración, lo que demuestra que el trámite parlamentario no fue pacífico y que la diversidad de ideologías plasmadas en los diferentes grupos con representación parlamentaria, convierte la cuestión de la libertad sindical en algo de contenido variable, según cual sea el criterio del partido político que goce de mayoría en las Cámaras en el momento en que se lleve a cabo la redacción de cualquier texto legal.

\section{La Minoria Catalana}

La postura de CiU, defendida por el diputado Roca Junyent, se concreta en las siguientes palabras: «Querer asegurar esta independencia (de los miembros del Poder Judicial) mediante las expresiones que se contemplan en el artículo $127 \ldots$ nos parece absolutamente impropio, impro- 
cedente e incluso con términos no del todo aceptables para las propias carreras judiciales. El querer comparar como causa de imposibilidad la de simultanear el ejercicio de la función judicial y cargos públicos, por ejemplo, con la mera pertenencia a partidos politicos o a sindicatos, nos parece que, evidentemente, no tiene correlación con las corrientes más modernas que se están introduciendo en este sentido en el Derecho Judicial europeo".

\section{El Grupo Comunista}

La opinión de este Grupo, negativa a la actual redacción del precepto, como la de Minoria Catalana, fue defendida por el diputado Solé Barberá, al mantener que «los jueces, magistrados y fiscales puedan pertenecer a una organización política o a un sindicato, porque entiendo que hay un cierto principio de infracción constitucional. El artículo $6 .^{\circ}$ de la Constitución define los partidos políticos como instrumento fundamental para la participación política, y, según la propia Constitución, los jueces son los protectores de las libertades y derechos fundamentales de los ciudadanos. Me parece que no cabe mayor error que privar del ejercicio de un derecho a quienes precisamente tienen como misión velar por el estricto y claro concepto de protección de este derecho».

\section{El Grupo Socialista}

La postura del PSOE, tal vez bastante diferente de la que mantendria en la actualidad en caso de que se reprodujera el debate, fue la clara oposición al texto con el que quedó conformado el artículo 127 definitivamente. Las tesis socialistas, defendidas por el diputado Pablo Castellano, se simbolizaban en la siguiente redacción para el artículo 127, apartado $1 .^{\circ}$, de la Constitución: "Los jueces, magistrados y fiscales, mientras se hallen en servicio activo, no pueden ejercer ninguna función pública o actividad profesional o mercantil ni desempeñar cargos directivos en partidos políticos, ni actuar en actos públicos como miembros de éstos." (Nótese que nada se dice respecto a sindicatos, por lo que debe entenderse una clara libertad al respecto.) Justifica ales términos por entender que no se puede cjamás confundir la indepen !encia de la función judicial con la apoliticidad de las personas, que seria absolutamente ilusorio tratar de convertir en un mero formalismo. El control de la independencia judicial no viene jamás ni por la represión ideolóçica ni por la discriminación política... a nadie se le va a prohibir ser miembro de un ideario, conservador 
o progresista; lo único que se hace es querer favorecer una determinada clandestinitis". "Si los jueces y magistrados son hombres que hemos dicho íntegros, y si son hombres preparados, y deben ser ellos los que administren justicia, entonces ¿dónde está el temor para que estos hombres puedan sindicarse libremente? ¿Es que desconfiamos de unos hombres que consideramos inicialmente íntegros? Parece ser que los convertimos en ciudadanos de segunda, no de primera o de tercera, o que desconfiamos de su integridad moral.»

\section{El Grupo Popular}

Las teorias de la entonces denominada Alianza Popular, fueron expuestas por su líder Manuel Fraga, que comenzó su exposición describiendo a los jueces y magistrados de una forma más propia de otra época, al definirlos como individuos «aislados tradicionalmente en una vida separada de la sociedad, con su traje negro de ceremonia; estos hombres, que en los pueblos tradicionales de España no pueden ir al casino, ni a jugar una partida de tresillo, que todos hemos visto en los viejos paseos de nuestras capitales de provincia, cerca de las Audiencias (yo los recuerdo en mi Lugo natal, paseando, el presidente en el centro, el fiscal a la derecha, y el resto, según su antigüedad, separados de los demás, porque este sacrificio les impone su servicio al pueblo); ésos son los magistrados que nosotros queremos que, para el pueblo y por el pueblo, venidos del pueblo, administren justicia».

Solamente en este contexto se puede entender la tesis de dicho Grupo parlamentario, al mantener que "esos jueces, que queremos competentes, responsables y por encima de toda sospecha, no pueden pertenecer a partidos ni a sindicatos; que, fieles a su viejo sacrificio a la sociedad (como el militar renuncia (?) también al derecho de huelga y al derecho de petición), tienen, en definitiva, el cauce, que ya se ha creado en el Proyecto Constitucional, de las asociaciones profesionales, pero en lo demás deben seguir como están».

\section{El Grupo Centrista}

Vamos, por último, a hacer alusión a la tesis que finalmente triunfó, y que fue defendida principalmente por el diputado del extinto partido Unión de Centro Democrático (UCD) José María Gil-Albert, con argumentos, entre otros, como éstos: «El problema donde realmente se suscita es 
por el prestigio y la naturaleza de su función (se refiere, lógicamente, a jueces y magistrados), por lo que tiene de singular y de relevante proyección social, por el efecto psicológico que puede producir, y que de hecho produce, el saber de antemano que quien tiene que juzgar participa y comparte públicamente unos postulados políticos determinados. Es decir, se trata de un cometido trascendente que requiere primordialmente ecuanimidad e independencia... La adscripción política de los jueces... produce recelo, quiérase o no, provoca en muchos casos una reacción de desconfianza, y... merece la pena evitar ese recelo y esa desconfianza».

El referido diputado centrista trató de desvirtuar los argumentos de los grupos parlamentarios que mantenían para jueces y magistrados únicamente la prohibición de ostentar cargos directivos en partidos políticos y sindicatos, así como de participar en actos públicos, por entender que tales grupos parlamentarios, de hecho, «están pidiendo una diferencia de trato, que están reconociendo lo mismo que reconocemos nosotros; y si estamos de acuerdo en el punto de partida, lo que sucede es que Unión de Centro Democrático no se conforma con soluciones intermedias, con soluciones equívocas ni contradictorias», para concluir afirmando que "esta naciente democracia... se fortalece con la prohibición de afiliación política y de sindicación de jueces y magistrados».

El texto aprobado por la Comisión mantuvo las limitaciones del informé de la Ponencia, e incluso añadió la prohibición de pertenecer a sindicatos, como ya se indicó más arriba, si bien autorizó las asociaciones profesionales de jueces y magistrados tras la aprobación de una enmienda in voce del diputado Roca Junyent. En el Pleno del Congreso se reprodujo el debate habido en la Comisión, al mantenerse como votos particulares las enmiendas defendidas en la Comisión.

Las distintas fases por las que atravesó el contenido del artículo 127.1 de la Constitución hasta alcanzar su actual perfil, fueron:

1. Articulo 117 del Anteproyecto (BOC 5 enero 1978): «Los jueces y magistrados, mientras se hallen en activo, no podrán desempeñar cargos públicos ni pertenecer a un partido politico».

Como se aprecia, el texto guarda silencio respecto a la posterior prohibición de los miembros del Poder Judicial de poder pertenecer a sindicatos y se refiere tan sólo al aspecto estrictamente político. También es significativa la actitud que observa al ignorar a los fiscales.

2. Artículo 119 del texto del Informe de la Ponencia (BOC 17 abril 1978): "Los jueces y magistrados, asi como los fiscales, mientras se hallen en activo, no podrán desempeñar cargos públicos, pertenecer a partidos políticos, sindicatos o integrarse en asociaciones profesionales». 
La evolución de este precepto demuestra con claridad cómo la materia recogida en el mismo era abordada con una total disparidad en períodos de tiempo muy breves, prueba inequívoca de las diversas ideas que sobre la cuestión tuvieron los representantes del pueblo a quienes se asignó la difícil tarea de redactar el texto constitucional. Se aprecia ya, en la nueva configuración, la aparición de los sindicatos y de los fiscales, y, sin embargo, se prohibe tanto a éstos como a jueces y magistrados, integrarse en asociaciones profesionales, cuestión ésta que después se resolvería en sentido positivo.

3. Artículo 121 del texto de la Comisión del Congreso ( $B O C 1$ julio 1978): "Los jueces y magistrados, asi como los fiscales, mientras se hallen en activo, no podrán desempeñar cargos públicos, ni pertenecer a partidos políticos o sindicatos. La Ley establecerá el sistema y modalidades de asociación profesional de los jueces y magistrados». Este texto fue el definitivo, con la modificación que introdujo posteriormente el Senado al añadir la palabra "otros" delante de cargos públicos, sin duda por entender que el mismo ejercicio de la función profesional ya conlleva el desempeño de un cargo público; esta cuestión fue defendida en una amplia intervención por el senador Villar Arregui, que obtuvo el voto favorable de la Cámara.

\section{DESARROLLO LEGISLATIVO}

Tomando como punto de partida (no podía ser de otra forma) el rígido contenido de la Constitución, el desarrollo legislativo de la materia que estamos analizando había quedado marcado definitivamente por aquella circunstancia, de tal manera que, en el futuro, al legislador no le quedaria otra alternativa que excluir a ciertos colectivos, ope legis, del ámbito de la libertad sindical, «pero con un régimen sometido a criterios particulares" (MOLERO MANGLANO).

\section{La Ley Orgánica de Libertad Sindical}

El artículo $1 .^{\circ}$ de la Ley Orgánica 11/1985, de 2 de agosto, de Libertad Sindical (LOLS), reconoce a todos los trabajadores el derecho a sindicarse libremente para la promoción y defensa de sus intereses económicos y sociales, $y$, a los efectos de dicha Ley, considera trabajadores tanto a los que sean sujetos de una relación laboral como a los funcionarios públicos. 
Después de este amplio reconocimiento del derecho, la LOLS, también en su artículo $1 .{ }^{\circ}$, enuncia las prohibiciones para los siguientes colectivos:

a) Los miembros de las Fuerzas Armadas y de los Institutos Armados de carácter militar (artículo 1.3), que han visto endurecer su situación en relación con las expectativas creadas por el artículo 28.1 de la Constitución, que no impuso al legislador esta vía prohibitiva, sino que le facultó para optar entre limitar, exceptuar o no exceptuar este derecho («la Ley podrá limitar o exceptuar el ejercicio de este derecho a las Fuerzas o Institutos Armados o a los demás cuerpos sometidos a disciplina militar»). Por cierto que, además de los integrantes de los Ejércitos de Tierra, Mar y Aire, a los que se prohibe eparticipar en sindicatos y asociaciones con finalidad reivindicativa" (artículo 181, Ley 85/78, de 28 de diciembre, que aprueba las Reales Ordenanzas de las Fuerzas Armadas), también se extiende la prohibición a la Guardia Civil, a pesar de la dependencia orgánica de este Cuerpo respecto del Ministerio del Interior y de la similitud de funciones con los diversos Cuerpos de Policía, a los que sí se permite la libertad de fundar sindicatos y afiliarse al de su elección, aunque regulándose este derecho por la Ley Orgánica de Fuerzas y Cuerpos de Seguridad y no por la LOLS.

\section{b) Los miembros de la carrera judicial y del Ministerio Fiscal.}

El artículo 1.4 de la LOLS dispone que "de acuerdo con lo dispuesto en el artículo 127.1 de la Constitución, los jueces, magistrados y fiscales no podrán pertenecer a sindicato alguno mientras se hallen en activo". No cabe, por tanto, mayor fidelidad, no sólo de contenido obviamente, sino también de redacción, con el texto constitucional. Sin embargo, contiene el precepto legal citado una disposición que, aunque ya conocida desde 1978, es preciso averiguar su alcance a fin de fijar el ámbito de la prohibición en el mismo contenida; me refiero en concreto a la circunstancia de que dicha actitud de interdicción sólo durará «mientras se hallen en activo" los sujetos por ella afectados. Con ello, se plantea el problema de determinar a qué situación afecta de las expresamente previstas en el artículo 348 de la Ley Orgánica del Poder Judicial, es decir, servicio activo, servicios especiales, excedencia voluntaria, excedencia forzosa y suspensión.

Parece razonable la solución propuesta por ALONSO GARCIA en el sentido de que, dada la caracterización que de las diversas situaciones enunciadas hace la LOPJ, las únicas de entre aquellas que permitirian el ejercicio del derecho, serían las de excedencia voluntaria y suspensión definitiva del servicio. Asi parece, además, reconocerse expresamente, y para el caso de los excedentes voluntarios, en el artículo 347.4 de la LOPJ, al imponer a los miembros de la carrera judicial que deseen presentarse 
como candidatos a las elecciones generales, autonómicas o locales, la obligación de solicitar la excedencia voluntaria.

\section{La Ley de derechos sindicales de los funcionarios públicos}

Ésta no es sino la forma en que habitualmente se conoce un instrumento legal, cuya denominación, aparentemente ambiciosa y de amplio contenido, es la de Ley $9 / 1987$, de 12 de mayo, de órganos de representación, determinación de las condiciones de trabajo y participación del personal al servicio de las Administraciones Públicas.

Dicha Ley supuso el desarrollo legislativo que cumplió el mandato contenido en la Disposición adicional $2 .^{a}$, párrafo $2 .^{\circ}$, de la LOLS, según la cual, el Gobierno debía remitir a las Cortes, en el plazo de un año y en desarrollo de lo previsto en el artículo 103.3 de la Constitución, «un proyecto de ley en el que se regulen los órganos de representación de los funcionarios de las Administraciones Públicas". En realidad, se limitó la LOR a crear, según PALOMEQUE, un «esquema normativo mimético» de la representación de los trabajadores regulada en el Estatuto de los Trabajadores, creando para los funcionarios públicos y en calidad de órganos "específicos" de representación de los mismos, a los delegados de personal y comités de empresa previstos en el ET.

En este contexto, el artículo $2 .^{\circ}$ de la LOR contiene tres excepciones, es decir, excluye de la regulación de la misma a tres tipos de funcionarios públicos: los miembros de las Fuerzas Armadas y de los Institutos Armados de carácter militar (cuya exclusión se deriva de la que inicialmente habian sufrido ya en la propia LOLS), los jueces, magistrados y fiscales, de los que hablaremos a continuación, y los miembros de los Cuerpos y Fuerzas de Seguridad, que se regirán por la Ley Orgánica de Fuerzas y Cuerpos de Seguridad, salvo los Cuerpos de Policía Local, a quienes será de aplicación la LOR.

La exclusión en la LOR de los jueces, magistrados y fiscales se realiza, según palabras de la propia Ley, "sin perjuicio del ejercicio de sus derechos de asociación profesional, de conformidad con lo dispuesto en el artículo 401 de la Ley Orgánica del Poder Judicial». Según Salvador DEL. REY GUANTER, se trata de colectivos funcionariales cuya exclusión es también una consecuencia derivada de una negación de la libertad sindical, aunque operada en términos distintos a la de las Fuerzas Armadas. En efecto, el artículo 127 de la Constitución, al establecer que aquellos funcionarios "... no podrán pertenecer a... sindicatos", no está dejando ningún tipo de opción al legislador ordinario, de forma que resulta obligado 
lo establecido en el artículo 1.4 de la LOLS en el sentido de que aquéllos «no podrán pertenecer a sindicato alguno mientras se hallen en activo». No obstante, y también a diferencia de los miembros de las Fuerzas Armadas, estos funcionarios públicos, sí podrán fundar y afiliarse a asociaciones, siempre que tengan como fines «la defensa de los intereses profesionales de sus miembros en todos los aspectos y la realización de actividades encaminadas al servicio de la justicia en general».

Lo indicado en esta última norma significa que tales funcionarios públicos tienen la posibilidad de desarrollar determinadas actividades de defensa profesional ante la Administración, pero las cuales ni se desarrollarán orgánicamente a través de representaciones unitarias (es decir, delegados y juntas de personal) o de sindicatos, ni a través de los derechos de negociación colectiva y consulta que contempla la LOR. En principio, por tanto, será un tipo muy peculiar de defensa de intereses, fundamentalmente a través de la via consultiva.

\section{La Ley Orgánica del Poder Judicial}

Resulta inevitable iniciar este apartado haciendo referencia a las ideas vertidas por el entonces ministro de Justicia, Fernando Ledesma, en el discurso que pronunció en la sesión plenaria del Congreso de los Diputados, celebrada el día 21 de marzo de 1985, al iniciarse el debate del dictamen de la Comisión de Justicia e Interior sobre el Proyecto de la LOPJ y durante el mismo, al manifestar que «quiero alzar la voz para mencionar que hay, a mi juicio, tres puntos que era urgente dejar claramente resueltos en el proyecto, y por eso el proyecto los ha asumido y los regula. Me refiero, en primer lugar, al reconocimiento y a la regulación del ejercicio de todos los derechos de participación que son compatibles con el desempeño de la función jurisdiccional y que deben ser reconocidos a los jueces. En este sentido, el proyecto de ley les atribuye una intervención, con respecto al principio de proporcionalidad... en el libre ejercicio de asociación profesional, acabando con una regulación del asociacionismo profesional judicial que, a mi juicio, no se compadece bien con los principios y exigencias constitucionales y que, de hecho, ha impedido que corrientes de opinión que existen dentro de la carrera judicial hayan podido constituirse en asociaciones».

El precepto de la LOPJ alusivo a la materia que está siendo analizada es el artículo 395, según el cual «no podrán los jueces o magistrados pertenecer a partidos políticos o sindicatos o tener empleo al servicio de los mismos...". Este texto, que es el que aprobó definitivamente el Congreso (recuérdese que se trata de una ley orgánica y sometida, por tanto, al trámite previsto en el artículo 81 de la Constitución) coincide en su tota- 
lidad con el texto remitido a las Cortes por el Gobierno y con el aprobado por el Pleno del Congreso, que pasó sin enmiendas al Senado, donde, a su vez, fue ratificado íntegramente, pasando de nuevo al Congreso donde alcanzó la definitiva redacción que se ha recogido más arriba. La deducción no puede ser más clara: perfecta y curiosa armonía entre los poderes Ejecutivo y Legislativo, sin que este último introdujera la más mínima enmienda o corrección, aunque sólo fuera de estilo.

De esta forma se repite la misma historia que en las leyes antes mencionadas, es decir, la ciega obediencia a la idea originaria que, a más de un autor, le ha llevado a reflexionar si no hubiera sido más adecuado evitar unos términos tan prohibitivos en la Constitución, diferiendo la cuestión para la norma legal pertinente, en este caso la propia LOPJ, y evitando así maniatar al legislador futuro en una cuestión en la que sólo el tiempo iría perfilando la conveniencia o no de negar tan drásticamente un derecho fundamental a un colectivo tan importante cuantitativa y cualitativamente. Sin embargo, el haberse producido los hechos de forma tan contraria a la expuesta (agravada por la propia rigidez de nuestra Constitución, cuyo procedimiento de reforma la convierte en prácticamente intocable), indica de forma patente cuál fue la voluntad represora de los legisladores constituyentes.

\section{El Estatuto Orgánico del Ministerio Fiscal}

Si el argumento que de forma más obsesiva y machacona preocupó, tanto a los redactores de la Constitución en el pasado como a una parte de la doctrina en el presente, fue el de negar a jueces y magistrados la libertad de afiliación política y sindical a cambio de la sagrada independencia que debe presidir en todo momento su actuación profesional, dicha teoría quiebra de forma estrepitosa en el caso de los miembros del Ministerio Fiscal. Téngase en cuenta que la propia Constitución, en su artículo 124, después de definir las funciones de aquél, afirma que éstas las ejercerá de acuerdo con los principios de unidad de actuación y dependencia jerárquica, estando encarnada esta última en el fiscal general del Estado, el cual (según el propio artículo 124, apartado 4) será nombrado por el Rey, «a propuesta del Gobierno», con lo que no nos será difícil intuir de quién va a depender de facto el Ministerio Fiscal.

Con este marco constitucional y, descartado el argumento de la independencia como soporte básico de la prohibición de pertenecer a partidos políticos y sindicatos, no se comprenden con facilidad los motivos para mantener tal postura respecto a un colectivo que ha sabido engancharse adecuada y beneficiosamente a la consideración, dotación y honores que tradicionalmente se ha concedido a los miembros del Poder Judicial, a pe- 
sar de no pertenecer a éste (aunque se haga referencia al Ministerio Fiscal en el mismísimo Título VI de la Constitución) y de la notable diferencia tanto de las funciones que desempeñan, como de la responsabilidad que asumen.

En cumplimiento del mandato constitucional (artículo 124.3) se promulgó el Estatuto del Ministerio Fiscal, por Ley 50/8t, de 30 de diciembre, cuyo artículo 54 reconoce a los integrantes del Cuerpo el derecho de asociarse profesionalmente, de forma análoga a las asociaciones judiciales reguladas con posterioridad en la LOPJ, por lo que se analizarán las mismas en el capitulo correspondiente.

\section{DISCREPANCIAS DOCTRINALES}

Los autores, no muchos por cierto, que se han dedicado a estudiar el tema de la libertad sindical de jueces, magistrados y fiscales, lo han hecho de forma tangencial $y$, tomando como referencia el precepto constitucional correspondiente, han elevado éste a la categoria de dogma, olvidando que incluso la misma Constitución es modificable, aunque el procedimiento previsto para ello sea tan rígido que actualmente parezca inviable. En todo caso, y dando por sentado que la anterior generalización acarrea no pocas injusticias, lo que si resulta hoy día constatable es que muy pocos se han atrevido a criticar el contenido del artículo 127 de la Constitución, generando asi a posteriori un consenso casi unánime sobre un precepto que fue tan duramente debatido por las fuerzas politicas con representación parlamentaria, que nada hacia presagiar esa complacencia posterior.

No obstante, haremos referencia seguidamente a las más autorizadas opiniones doctrinales sobre la cuestión planteada, aludiendo en primer lugar a aquellas que se han decantado de forma favorable por la negación del derecho establecida en nuestra Carta Magna.

ALONSO GARClA entiende que la razón determinante de esta prohibición no puede ser otra, intencionalmente al menos, que la de garantizar la independencia e imparcialidad como valores esenciales del poder judicial frente a las posibles opciones partidistas.

En análogos términos se pronuncia MONTOYA MELGAR, para quien el alcance básico que persigue la sustitución de la afiliación al sindicato por la incorporación profesional no parece que sea otro que impedir el acceso de jueces, magistrados y fiscales a centrales sindicales de signo partidista y reforzar consecuentemente la imparcialidad de los referidos funcionarios de la Justicia. 
Para MOLERO MANGLANO, es evidente que el fundamento de esta exclusión reside en la necesidad de independencia absoluta con que la Constitución quiere dotar el ejercicio de sus funciones, preocupación que es patente a lo largo del título sexto, que la Constitución dedica al Poder Judicial, y en las normas de desarrollo del mismo, muy especialmente en la Ley Orgánica del Poder Judicial, de 10 de enero de 1980, ya derogada.

Un leve matiz diferente aporta GARCÍA ABELLAN, al mantener que el régimen asociativo extrasindical de estos colectivos responde a un punto medio de equilibrio entre la función que les es atribuida y la evidente profesionalización de sus titulares, de la que se derivan intereses legítimos, aun cuando queden excluidos a tal efecto los medios de acción que son propios y tipicos de los sindicatos.

Los que se han pronunciado de forma crítica contra la prohibición constitucional, aunque en menor número, también merecen ser reflejados aquí por la reconocida autoridad de sus nombres.

Así, J. A. BELLOCH califica de artificiosa la prohibición para los jueces de integrarse en partidos políticos y sindicatos; no obstante, estima conveniente que los jueces no ejerzan funciones directivas en los partidos políticos y se muestra partidario de la autonomía del movimiento judicial respecto del sindicalismo "de clase" en su conjunto.

Para MONTERO AROCA, la solución de nuestra Constitución es claramente insatisfactoria. Pero la opinión doctrinal más crítica la ha emitido, sin duda, OJEDA AVILÉS, el cual entiende que en el debate parlamentario del artículo 127.1 de la Constitución se aludió a la «dignidad de la Judicatura como incompatible con el sindicalismo, arrojando indirectamente un peyorativo juicio de valor, por demás trasnochado, sobre los sindicatos". A su juicio, "el mandato constitucional se tradujo en la creación de algo similar a un Colegio Profesional Sindical alejado de las centrales obreras».

El propio Tribunal Constitucional (sentencia 108/1986, de 29 de julio) ha destacado que «la situación estatutaria de los jueces es más rigurosa que la de los funcionarios de la Administración Civil del Estado, a los que se reconoce el derecho a la sindicación, con los efectos que ello puede acarrear, derecho que se niega expresamente a los miembros de la Magistratura». ALONSO OLEA, al comentar esta sentencia no extrae «ninguna consideración especial» (?) «de esta rigurosidad especial de la situación estatutaria del funcionario judicial». 


\section{LAS ASOCIACIONES PROFESIONALES}

Partiendo de la prohibición constitucional, sólo queda analizar la única posibilidad que se les permite actualmente a los miembros de las carreras judicial y fiscal para la defensa de sus intereses legítimos 0 , por utilizar una frase de la propia Constitución (artículo $7 .^{\circ}$ ), para la «defensa y promoción de los intereses económicos y sociales que les son propios".

\section{Antecedentes históricos}

Sin duda, el más importante de éstos y el que ha capitalizado el protagonismo del fenómeno sindical en los colectivos judiciales, ha sido «Justicia Democrática», movimiento judicial de resistencia antifranquista en el que se integraron unos cuantos jueces, fiscales y secretarios judiciales.

"Justicia Democrática» elaboró su documento fundacional sobre Justicia y Gobierno en 1971, empezando a funcionar en 1973, coincidiendo con la elaboración del Proyecto de Ley de Bases Orgánicas de la Justicia, es decir, en unos momentos en los que, a juicio DE CAVERO, el régimen autocrático entra en un letargo decadente como consecuencia de la ancianidad y precaria salud del anterior Jefe del Estado, y el citado movimiento asociativo comienza a publicar sus críticas a una legislación cuyas posibilidades de subsistencia futura ya empieza a considerar tan problemática como la del propio régimen autocrático.

Dicho colectivo optó abiertamente por asumir una función decididamente política y no dudó en participar, según J. A. BELLOCH, junto a partidos politicos, sindicatos y otros grupos sociales, en la estrategia general que, contra la dictadura militar, se articuló por la oposición en su conjunto, aportando concretamente una visión avanzada de la doctrina de los derechos humanos y concretas propuestas para una articulación democrática de la Justicia.

Por tanto, se puede afirmar que "Justicia Democrática", que actuaba en una casi absoluta clandestinidad, perseguía unos objetivos que iban más allá de la estricta reivindicación profesional, adoptando una posición política progresista, cercana a la mantenida por los partidos de izquierda (IÑIGO CAVERO).

OJEDA AVILÉS cita también como «fermentos del sindicalismo judicial» a la Junta de Jueces de la Audiencia Provincial de Barcelona, ac- 
tiva a comienzos de 1979, asi como un pretendido sindicato de la Administración de Justicia de Cataluña que fue desestimado en 1977 por un Juzgado de Primera Instancia de Madrid a solicitud del Ministerio Fiscal; en marzo de 1979, un centenar de jueces, magistrados y fiscales crean la Asociación Profesional de Jueces y Fiscales de la Audiencia Territorial de Cataluña, y en abril del mismo año surge la Unión Territorial de Magistrados, Jueces y Fiscales de Andalucia, por fusión de dos asociaciones de las Audiencias de Sevilla y Granada.

La Ley Orgánica 1/1980, de 10 de enero, del Consejo General del Poder Judicial, primer desarrollo normativo de la Constitución en esta materia, estableció que los vocales del Consejo de procedencia judicial serían elegidos por todos los jueces y magistrados en servicio activo (artículo 12), disponiendo que las candidaturas habrían de estar avaladas por un 10 por 100 de los electores o por una "asociación profesional» válidamente constituida (artículo 14.4) completando el sistema con la exigencia de la adhesión de un 15 por 100 como mínimo de todos los jueces y magistrados para que pudiera constituirse válidamente una asociación (Disposición Adicional Segunda).

Ante el proceso electoral que se avecinaba para el naciente Consejo General, se constituyó en febrero de 1980 la Asociación Profesional de la Magistratura, con más de 500 jueces y magistrados de los 2.000 existentes en aquel momento, con unos estatutos marcadamente descentralizadores; las elecciones a sus cargos directivos en el mes de marzo dieron el triunfo a candidaturas conservadoras, en un momento en el que ya se habían integrado en la Asociación las dos terceras partes de los jueces y magistrados estatales (OJEDA).

En las primeras elecciones de vocales del Consejo, celebradas en 1980, los candidatos de la "Asociación Profesional de la Magistratura" consiguieron una amplia ventaja sobre los candidatos procedentes de "Justicia Democrática", al operar un sistema de elección mayoritario. Quedó asi la APM como única Asociación, transformándose "Justicia Democrática» en una corriente organizada dentro de la propia Asociación Profesional. En enero de 1984 se constituyó una nueva corriente, de orientación moderada en este caso, denominada «Francisco de Vitoria».

De esta manera una sola Asociación aglutinó todas las corrientes de opinión existentes en dicha época en el asociacionismo judicial. Así convivieron durante los primeros años de la nueva experiencia hasta que en 1984, con ocasión del IV Congreso Nacional celebrado en marzo, «Jueces para la Democracia» y "Francisco de Vitoria" se retiraron de la Asociación para orientarse hacia la creación de asociaciones independientes de la APM. Paradójicamente, una de las causas de las escisión fue la elección de los doce vocales judiciales del Consejo General del Poder Judicial. Según datos de la consulta efectuada por la APM en junio-julio 
de 1987, la actual situación plural es indeseable para la gran mayoría de los jueces y magistrados.

En resumen, y desde el punto de vista ideológico, se puede afirmar que en la actualidad existen tres asociaciones de jueces y magistrados: "Asociación Profesional de la Magistratura", de tendencia conservadora y corporativa, mayoritaria dentro de la judicatura española; «Jueces para la Democracia", progresista, que asume, según sus propios Estatutos, "contribuir decididamente a la promoción de las condiciones que hagan efectivos los valores que la Constitución proclama", y la Asociación "Francisco de Vitoria», prácticamente testimonial, situada ideológicamente en una posición intermedia entre las dos organizaciones anteriores (PALOMEQUE).

La aparición del Estatuto Orgánico del Ministerio Fiscal permitió que se creara en 1981 la "Asociación Profesional de Fiscales", conservadora y mayoritaria, que rápidamente acreditó su implantación en las elecciones celebradas para la elección de miembros del Consejo Fiscal, y la «Unión Progresista de Fiscales", cuyo primer Congreso se celebró en Madrid en junio de 1986.

\section{Naturaleza juridica: ¿verdaderos sindicatos?}

Tampoco ha existido unanimidad en cuanto a la naturaleza jurídica de las asociaciones profesionales. Generalmente se ha admitido la tesis de que se trata de una nueva especie con fisonomía propia, resistiéndose a una catalogación en las formas tradicionalmente conocidas de unirse cualquier colectivo profesional para la defensa de sus intereses.

La misma Exposición de Motivos de la Ley Orgánica del Poder Judicial ya anunció que «la materialización de los principios de pluralismo y participación de que se quiere impregnar al gobierno del Poder Judicial impone una profunda modificación de la actual regulación del derecho de asociación profesional que el artículo 127.1 de la Constitución reconoce a jueces, magistrados y fiscales. El régimen transitorio de libertad asociativa hasta ahora existente contiene restricciones injustificadas a las que se pone fin. De ahi que esta Ley Orgánica reconozca el derecho de libre asociación profesional con la única limitación de no poder llevar a cabo actuaciones políticas ni tener vinculaciones con partidos políticos o sindicatos».

De ingenua cuando menos habría que calificar esta declaración de intenciones de la Ley, sobre todo si, como afirma J. A. BELLOCH, enten- 
demos que la más peculiar señal de identidad de las asociaciones profesionales de jueces radica en ser, ante todo, «instrumentos fundamentales de participación de los jueces en la vida política». La clave de esta concepción radica en el término «instrumentos fundamentales», pues en esta circunstancia se basa precisamente la peculiar forma de entender este singular movimiento asociativo, distinguiéndolo de otros afines. MAZA MARTÍN definió a las asociaciones judiciales como «algo curiosamente original y exótico".

Las definiciones y calificativos que la doctrina ha ideado para desentrañar la esencia de las asociaciones profesionales podrian multiplicarse, pues los esfuerzos en tal sentido han sido loables. Sin embargo, la similitud de aquéllas con los sindicatos es, en la mayor parte de sus aspectos, notoria.

Partiremos del concepto de sindicato que formularon los esposos Webb en 1894, revisado en 1920, y que es todo un clásico en el mundo del Derecho del Trabajo: «El sindicato es una asociación permanente y autónoma, sin fin de lucro, de trabajadores por cuenta ajena, para el progreso económico y social de sus miembros, especialmente para el mantenimiento y mejora de sus condiciones de trabajo a través de la contratación colectiva». Si analizamos con rigor los elementos integrantes de esta completa definición, descubriremos inmediatamente la razón del anterior aserto.

Es evidente que las asociaciones profesionales son, igual que los sindicatos, asociaciones permanentes y autónomas sin fin de lucro. La duda puede surgir en el diferente ámbito subjetivo de unas y otros, pues mientras las asociaciones profesionales están integradas, en el caso que nos ocupa, por jueces y magistrados o por fiscales, los sindicatos se crean por y para trabajadores por cuenta ajena. Es cierto que los colectivos mencionados no se regulan por el Estatuto de los Trabajadores, pero tampoco los funcionarios públicos $y$, sin embargo, tienen una amplia libertad sindical (a pesar de sus «peculiaridades») según se dispone en la propia Ley Orgánica de Libertad Sindical de 1985. Por tanto, esta diferencia subjetiva no puede servir para distinguir a unas de otros, salvo que acudamos a criterios corporativistas.

También parece claro que las asociaciones profesionales se constituyen «para el progreso económico y social de sus miembros»; mantener lo contrario sería tanto como afirmar que no sirven para nada. La propia Constitución, en su artículo $7 .^{\circ}$, reconoce que «la defensa y promoción de los intereses económicos y sociales que les son propios" es el fin genérico de los sindicatos, y más concretamente, como los esposos Webb anticiparon, el «mantenimiento y mejora de sus condiciones de trabajo», legitima aspiración que también anima, lógicamente, el espíritu de cualquier asociación profesional. 
Así, por poner un ejemplo significativo, MARÍN CASTAN, miembro de la Asociación de Jueces y Magistrados "Francisco de Vitoria», destaca las que serán, entre otras, funciones de aquéllas: exponer ante el Consejo General del Poder Judicial las legitimas aspiraciones de los jueces en materia retributiva y de formación y perfeccionamiento, así como «negociar con el Gobierno las condiciones de trabajo de jueces y magistrados".

La forma mediante la cual consiguen los sindicatos habitualmente la finalidad antes mencionada es la contratación o negociación colectiva. A estas alturas parece poco probable que alguien se atreva a negar que las importantes mejoras obtenidas para los años 1989 y siguientes (sobre todo en el aspecto económico) por las asociaciones profesionales de jueces, magistrados y fiscales para sus representados, se deben a una auténtica negociación colectiva, sea cual fuere la denominación que las partes negociadoras le hayan querido asignar.

Por todo ello, se puede concluir deduciendo una identidad sustancial entre sindicatos y asociaciones profesionales, no sólo desde el punto de vista conceptual, sino también atendiendo a los fines y medios perseguidos por todos. Los propios jueces se refieren a uaspectos sindicales" en las asambleas que llevan a cabo (en tal sentido, la convocatoria de reunión del Comité Permanente de "Jueces para la Democracia» para el día 12 de noviembre de 1989). En esta misma línea, OJEDA AVILÉS mantiene que el lugar apropiado de las asociaciones profesionales está entre los sindicatos, con un especial régimen jurídico desarrollado por una normativa ad hoc, por lo que la diferencia entre unas y otros «no es de sustancia sino de régimen jurídico".

Incluso entre los propios miembros de las carreras judicial y fiscal existe el pleno convencimiento del carácter sindical inequívoco de sus asociaciones profesionales, aunque pocos sean los que se atrevan a manifestar públicamente este parecer. Entre estos últimos cabe destacar la opinión de DOLZ LAGO, miembro de la "Unión Progresista de Fiscales", para quien las asociaciones profesionales «en realidad son sindicatos".

\section{El régimen juridico}

a) Asociaciones de jueces y magistrados

El mandamiento establecido en el artículo 127 de la Constitución se materializó, en lo que a los integrantes del Poder Judicial se refiere, en el artículo 401 de la Ley Orgánica del Poder Judicial. La doctrina se ha he- 
cho eco del acierto que ha supuesto el prescindir de criterios numéricos para la existencia de una asociación profesional pues, en caso contrario, se podría producir un atentado a la libertad de asociación, que propiciaría, como en su día ocurrió, una unidad asociativa casi impuesta; esto hubiera producido una clara desnaturalización de dicho movimiento acercándolo a otros sectores profesionales de colegiación única y obligatoria. No obstante, se ha mantenido la necesidad de acompañar al texto de los estatutos la relación de los afiliados, con la finalidad de evitar la doble afiliación, lo cual supone «un riesgo de que sea quebrantado el artículo 16.2 de la CE» (comentarios a la LOPJ; COLEX).

Los principios contenidos en el referido artículo 401 de la LOPJ, que FAIRÉN GUILLÉN ha calificado de «libertad limitada» se regulan de la siguiente manera: «De acuerdo con lo establecido en el artículo 127 de la Constitución, se reconoce el derecho de libre asociación profesional de jueces y magistrados, que se ejercerá de acuerdo con las reglas siguientes:

1. a "Las asociaciones de jueces y magistrados tendrán personalidad jurídica y plena capacidad para el cumplimiento de sus fines.»

2. «Podrán tener como fines lícitos la defensa de los intereses profesionales de sus miembros en todos los aspectos y la realización de actividades encaminadas al servicio de la Justicia en general. No podrán llevar a cabo actividades políticas ni tener vinculaciones con partidos políticos o sindicatos."

Topamos de nuevo en este precepto legal con la dificil distinción teórica y práctica entre las actividades políticas y las profesionales y/o sindicales. Aunque no sea éste el momento de tratar de deslindar ambos terrenos, parece claro que la norma de referencia está redactada en términos tan amplios que difícilmente podrá evitar las actividades políticas de las asociaciones profesionales. RODRIGUEZ AGUILERA recuerda acertadamente que la legalidad que venía derivándose de la LOPJ (la de 1870, obviamente) había permitido que jueces, magistrados y fiscales no sólo pertenecieran al partido único (FET y de las JONS) sino que se venía exigiendo a los mismos «el juramento de fidelidad a sus principios y reservaba todos sus cargos de dirección de la carrera judicial, y muchos que no lo eran, solamente a quienes fueran calificados de especialmente idóneos".

3. "Las asociaciones de jueces y magistrados deberán tener ámbito nacional, sin perjuicio de la existencia de secciones cuyo ámbito coincida con el de un Tribunal Superior de Justicia.»

Esta regla, además de fijar el ámbito territorial de tales asociaciones, pretendió favorecer la unidad estatal de la organización judicial. 
$4 .^{a}$ «Los jueces y magistrados podrán libremente asociarse o no a asociaciones profesionales."

Regla lógica, por otra parte, pues lo contrario hubiera acercado estas asociaciones a otro tipo de Colegios profesionales, e innecesaria, cuyo espíritu habría que encuadrar en el artículo 28.1 de la Constitución cuando dispone que nadie podrá ser obligado a pertenecer a un sindicato (libertad sindical negativa).

$5 .^{\text {a }}$ «Sólo podrán formar parte de las mismas quienes ostenten la condición de jueces y magistrados en servicio activo. Ningún juez o magistrado podrá estar afiliado a más de una asociación profesional.»

6. ${ }^{\text {a }}$ «Las asociaciones profesionales quedarán válidamente constituidas desde que se inscriban en el Registro que será llevado al efecto por el Consejo General del Poder Judicial. La inscripción se practicará a solicitud de cualquiera de los promotores, a la que se acompañará el texto de los Estatutos y una relación de afiliados. Sólo podrá denegarse la inscripción cuando la asociación o sus Estatutos no se ajustaren a los requisitos legalmente exigidos.»

Contiene esta regla 6 . $^{\text {a }}$ un sistema de control jurisdiccional y no administrativo, por lo que debe entenderse que el Consejo General del Poder Judicial sólo podrá negarse a inscribir una asociación profesional basándose en aspectos formales de los requisitos legales, quedando los aspectos materiales reservados al reconocimiento de los Tribunales de Justicia. Por tanto, la intervención administrativa debe quedar relegada al trámite indispensable del depósito de estatutos, como mera exigencia de publicidad.

7. ${ }^{\mathrm{a}}$ «Los Estatutos deberán expresar, como mínimo, las siguientes menciones:

a) Nombre de la asociación.

b) Fines específicos.

c) Organización y representación de la asociación. Su estructura interna y funcionamiento deberán ser democráticos.

d) Régimen de afiliación. 
e) Medios económicos y régimen de cuotas.

f) Formas de elegirse los cargos directivos de la asociación.»

Nótese la gran similitud existente entre el contenido mínimo estatutario establecido en este artículo de la LOPJ y el previsto para los sindicatos en el artículo $4 .^{\circ}$ de la Ley Orgánica de Libertad Sindical.

Los estatutos de la asociación profesional se configuran como la norma interna básica de la misma, expresiva de su derecho colectivo de autoorganización. FAIRÉN GUILLÉN entiende que en la expresión «fines específicos" es donde, a base de gongorismos y oscurantismos, se podrian introducir finalidades o conexiones políticas.

8. " «La suspensión o disolución de las asociaciones profesionales quedará sometida al régimen establecido para el derecho de asociación en general.»

9. " «erán de aplicación supletoria las normas reguladoras del derecho de asociación en general.»

Con estas reglas se pretendió insertar el régimen de las asociaciones profesionales en el artículo 22 de la Constitución, con exclusión del 28.1.

b) Asociaciones de fiscales

La regulación de las asociaciones profesionales de los fiscales es sustancialmente idéntica a la referente a jueces y magistrados. En realidad, es anterior a ésta pues la LOPJ se limitó básicamente a transcribir el artículo 54 del Estatuto Orgánico del Ministerio Fiscal.

Las diferencias entre ambos regimenes jurídicos son las siguientes, sirviendo para los restantes aspectos lo expuesto más arriba, que se da ahora por reproducido:

- El artículo 54 del EOMF no prohibe expresamente a los fiscales llevar a cabo actividades políticas ni tener vinculaciones con partidos o sindicatos, aspecto que sí recoge el artículo 401 de la 
LOPJ. Habrá que entender que se trata de una mera omisión involuntaria, pues lo contrario nos llevaria a conclusiones cuando menos contradictorias. La redacción del artículo 59 del EOMF tiene distinto alcance al expuesto antes.

- El Registro de las asociaciones profesionales de fiscales se lleva en el Ministerio de Justicia, mientras que en el CGPJ se encuentra el referente a los miembros del Poder Judicial.

- No hace referencia el artículo 54 EOMF al ámbito territorial de las asociaciones de fiscales, que habrá que entender análogo a las de jueces y magistrados.

- La diferencia más notable es la facultad que se encomienda al fiscal general del Estado para instar la disolución de las asociaciones profesionales de fiscales que incurrieren en actividades contrarias a la Ley o que excedieren del marco de los Estatutos. Una vez instado el juicio declarativo ordinario, la competencia para acordar la disolución corresponderá a la Sala 1. ${ }^{2}$ del Tribunal Supremo, que, con carácter cautelar, podrá acordar la suspensión de la asociación.

\section{CONCLUSIONES}

A la vista de los planteamientos expuestos en el presente estudio, parece desprenderse la prisa (más bien, precipitación) del legislador constituyente por dejar zanjado desde el principio un tema sobre el cual no existió el consenso necesario para arbitrar una solución tan contundente. Parece como si en los redactores de la Constitución española hubiera cundido el temor a posibles cambios posteriores, y determinadas materias, entre ellas la libertad sindical de jueces, magistrados y fiscales quedaron amarradas en unos términos tan inequívocos como sospechosos.

Debe insistirse, en relación con lo anterior, en la conveniencia de haber postergado la regulación de esta materia a una ley (la Ley Orgánica del Poder-Judicial y el Estatuto Orgánico del Ministerio Fiscal parecen los lugares más adecuados para ello), que hubiera permitido acomodar los tiempos cambiantes a las situaciones correspondientes. Solución ésta que ya se adoptó con otros colectivos profesionales (significativamente las Fuerzas Armadas, para las que la Constitución dejó una puerta abierta -que la legislación posterior se encargaría de cerrar - al redactarse el ar- 
tículo 28.1 de forma que no eliminara tan drásticamente la libertad del legislador).

No menos sospechosa parece la conformista actitud observada por la mayor parte de los funcionarios afectados por la prohibición, a quienes no parece preocuparles el actual statu quo, debido a la posibilidad que tienen de fundar ( $y$ afiliarse $a$ ) asociaciones profesionales, las cuales constituyen el medio idóneo para realizar actividades sindicales (muchos de sus asociados así las denominan) que en nada tienen que envidiar a las que han constituido habitualmente los medios de lucha de los llamados sindicatos de clase.

Téngase en cuenta, por otra parte, que la libertad sindical es eficaz si va acompañada de las medidas que habitualmente la secundan y que constituyen sus auténticos pilares: la negociación colectiva y la huelga. Esta última no ha sido precisa aún para el logro de las reivindicaciones de jueces, magistrados y fiscales (aunque un importante número de jueces y magistrados estuvo en algún momento dispuesto a ejercitar dicho derecho), pero la negociación colectiva entre aquéllos y el Gobierno y la Administración les permitió alcanzar la mayor parte de las pretensiones (sobre todo las económicas) que propugnaban.

Tanto el controvertido trámite parlamentario en torno al artículo 127 de la Constitución, como las discrepancias doctrinales apuntadas a lo largo del presente estudio, confirman la falta de consenso y la relatividad reinante en esta materia.

Que nadie pretenda ver en estas líneas una actitud beligerante y apologética en contra de la Constitución, a la que deseo una larga y próspera existencia; simplemente he tratado de adoptar una actitud crítica hacia los redactores de aquélla, y más en concreto a la precipitación por negar un derecho en base a unas razones que no comparto.

No obstante, las asociaciones profesionales, como sucedáneos de los sindicatos, han cumplido hasta el momento su función de constituir el instrumento de expresión adecuado para las inquietudes y reivindicaciones de unos profesionales tan merecedores de ese derecho como cualquier otro colectivo. 


\section{BIBLIOGRAFIA}

Alonso García, Manuel: Curso de Derecho del Trabajo, Ariel, Barcelona 1987.

Alonso OLEA, Manuel: Jurisprudencia constitucional sobre trabajo y Seguridad Social, Civitas, Madrid 1986.

BELLOCH JULBE, Juan Alberto: "Notas sobre el Asociacionismo Judicial», Revista Poder Judicial, Madrid 1986.

Bermúdez de la Fuente, José L., y otros: Ley Orgánica del Poder Judicial, Publicaciones Abella, Madrid 1986.

Cavero Lataillade, Íñigo, y otros: Comentarios a las Leyes Políticas. Constitución Española de 1978, tomo IX, Editorial Revista de Derecho Privado, Madrid 1987.

Constitución Española. Trabajos parlamentarios, Servicio de Estudios y Publicaciones de las Cortes Generales, Madrid 1980.

Diario de Sesiones del Congreso de los Diputados, núm. 191.

Fairén Guillén, Víctor: Comentarios a la Ley Orgánica del Poder Judicial de 1 de julio de 1985, Editorial Revista de Derecho Privado, Madrid 1986.

Garcla Abellán, Juan: Curso de Derecho Sindical, Universidad de Murcia, 1986.

Justicia Democratica : Los jueces contra la Dictadura, Tucar Ediciones, Madrid 1978.

Marin CASTAN, Francisco: «Funciones de las Asociaciones de Jueces y Magistrados", Revista Poder Judicial, Madrid 1986.

Maza Martín, José Manuel: "Asociaciones de Jueces y Magistrados», Revista Poder Judicial, Madrid 1986.

Molero Manglano, Carlos: Libertad Sindical, Universidad Pontificia de Comillas, Madrid 1987.

Montero Aroca, Juan: Materiales para el estudio de la Ley Orgánica del Poder Judicial, Centro de Publicaciones del Ministerio de Justicia, Madrid 1985. 
Montoya Melgar, Alfredo: Derecho del Trabajo, Tecnos, Madrid 1987.

OJeda AvILEs, Antonio: Derecho Sindical, Tecnos, Madrid 1988.

Palomeque López, M. Carlos: Derecho Sindical Español, Tecnos, Madrid 1988.

Del Rey Guanter, Salvador: Comentarios a la Ley de Organos de representación, determinación de las condiciones de trabajo y participación del personal al servicio de las Administraciones Públicas, Ministerio para las Administraciones Públicas, Madrid 1988.

Rodriguez Aguilera, Cesáreo: El Poder Judicial en la Constitución. Editorial Bosch, Barcelona 1980.

Serrano Alberca, José M., y otros: Comentarios a la Constitución, Cívitas, Madrid 1985.

Terceras Jornadas de Derecho Judicial, Centro de Publicaciones del Ministerio de Justicia, Madrid 1987. 